\title{
Mineral accretion in the human fetus
}

\author{
S RYAN, ${ }^{*}$ P J CONGDON,${ }^{*}$ J JAMES,$\dagger$ J TRUSCOTT, $\ddagger$ AND A HORSMAN $\ddagger$ \\ ${ }^{*}$ Regional Neonatal Surgical and Intensive Care Unit, †University Department of Paediatrics, and the $\ddagger$ MRC \\ Bone Mineralisation Group, Department of Medical Physics, The General Infirmary, Leeds
}

SUMMARY Bone mineral content of the mid forearm was measured by photon absorptiometry in 73 white singletons ( 36 boys, 37 girls) born between 18 and 43 weeks' gestation. Results obtained within two weeks of birth for liveborn infants were used to establish bone mineral deposition curves approximating normal in utero development. Results for stillborn infants indicated a retardation of bone mineralisation relative to liveborn infants. This has important implications concerning previous estimates of daily calcium needs for preterm infants.

Eleven liveborn Asian singletons and nine pairs of white twins were examined similarly. With respect to bone mineral content, weight, and crown-heel length, Asians with gestational ages over 35 weeks and twins were closely comparable with their white singleton peers. Asians under 35 weeks tended to be smaller than white singletons of comparable age.

Single photon absorptiometry has become an important technique for the investigation of disorders of skeletal mineralisation in the newborn. ${ }^{1-3}$ It has been shown to be an accurate and reproducible measure of bone mineral content in the fetus ${ }^{4}$ and to be more sensitive in detecting bone mineral deficit in the newborn than conventional radiography. ${ }^{3}$

As part of a larger study of bone mineralisation in the neonate, we obtained measurements of bone mineral content and anthropometric data on fetuses and infants born between 18 and 43 weeks' gestation. The data on liveborn white infants have been taken to represent normal values for bone mineralisation in utero in relation to gestational age. These values are required as a reference against which postnatal changes in bone mineral content, measured longitudinally in individual infants, can be assessed. At any gestational age the normal rate of mineralisation in utero is most likely the optimum figure against which the success of postnatal dietary supplementation should be judged.

Daily dietary requirements for calcium and phosphorus after birth have previously been estimated from results of whole body analysis of infant cadavers, some of the infants having been stillborn. ${ }^{5}$ At any gestational age, however, systematic differences might exist between skeletal mineral content in stillborn and liveborn infants, and hence the daily mineral requirement derived using that approach might be invalid. We therefore studied white stillborn infants and spontaneous abortions as a sep- arate group in order to find out whether or not they are an acceptable model for estimating the postnatal mineral requirements of preterm infants.

Observations of Asian singletons and white twins have also been compared with results obtained in white singletons.

\section{Patients and methods}

Seventy three white singleton infants were studied ( 36 boys, 37 girls). Infants born after 28 weeks' gestation who showed extreme intrauterine growth retardation - that is, those whose weight was below the third centile on standard charts - were excluded from the study. ${ }^{6}$ Gestational age, assessed to the nearest week by maternal dates, ranged from 18 to 43 weeks inclusive. Twelve of the boys and four of the girls were either spontaneous abortions or stillborn. (Such infants are collectively described below as 'stillborn infants'.) Causes of abortion or stillbirth were heterogeneous with the most common cause being abruptio placentae. The infants were grouped by gestational age in one week intervals, keeping liveborn and stillborn infants separate. The number in each subgroup, together with weight at birth (measured in all except four infants), is given in table 1.

Eleven liveborn Asian singletons and both members of nine white twin pairs born during the three year period of the study were also examined. In two pairs of twins both twins were stillborn. Basic 
Table 1 Mean weight at birth in white singletons grouped by gestational age. Where the data are incomplete the number of infants for whom that mean was computed is given in parentheses

\begin{tabular}{|c|c|c|c|c|}
\hline \multirow{2}{*}{$\begin{array}{l}\text { Gestational age } \\
\text { (weeks) }\end{array}$} & \multicolumn{2}{|c|}{ Boys } & \multicolumn{2}{|l|}{ Girls } \\
\hline & No & $\begin{array}{l}\text { Weight } \\
\text { (g) }\end{array}$ & No & $\begin{array}{l}\text { Weight } \\
(g)\end{array}$ \\
\hline \multicolumn{5}{|c|}{ Stillbirths } \\
\hline 18 & 1 & 195 & - & - \\
\hline 19 & 1 & 171 & - & - \\
\hline 22 & 2 & 463 & - & - \\
\hline 23 & 2 & 435 & 1 & 379 \\
\hline 25 & - & - & 2 & 626 \\
\hline 26 & 1 & 635 & - & - \\
\hline 27 & 1 & 900 & - & - \\
\hline 28 & - & - & 1 & 1336 \\
\hline 31 & 1 & 1620 & - & - \\
\hline 33 & 1 & 1730 & - & - \\
\hline 35 & 1 & 3035 & - & - \\
\hline 39 & 1 & 3490 & - & - \\
\hline \multicolumn{5}{|c|}{ Live births } \\
\hline 26 & - & - & 1 & 795 \\
\hline 27 & - & - & 3 & 1147 \\
\hline 28 & 2 & 1375 & - & - \\
\hline 29 & 1 & 1490 & 2 & 1475 \\
\hline 30 & 2 & 1605 & 2 & 1438 \\
\hline 31 & 3 & 1650 & 6 & 1491 \\
\hline 32 & 2 & 2025 & 5 & 1776 \\
\hline 33 & - & - & 2 & 2200 \\
\hline 34 & 1 & 2550 & - & - \\
\hline 35 & - & - & 1 & 2760 \\
\hline 36 & - & - & 1 & - \\
\hline 38 & 1 & 3030 & 1 & 2980 \\
\hline 39 & 4 & 3580 & - & - \\
\hline 40 & 5 & $3903(3)$ & 6 & 3510 \\
\hline 41 & - & - & 2 & 3945 \\
\hline 42 & 1 & 3700 & 1 & 3420 \\
\hline 43 & 2 & $4230(1)$ & - & - \\
\hline
\end{tabular}

information on Asians and twins is given in tables 2 and 3 respectively. Weight at birth was not measured in one Asian singleton.

Bone mineral content of the right mid forearm was assessed in each case by single photon absorptiometry using a scanner designed specifically for measuring infants. Informed parental consent to carry out absorptiometry was obtained for all liveborn infants. Details of the scanner and its calibration have been given in earlier publications. ${ }^{34}$ The method entails measurement of the absorption of a narrow beam of monochromatic radiation as it slowly traverses the forearm. The radiation exposure is extremely small; skin entrance dose is $0.03 \mathrm{mGy}$ ( 3 millirads) per investigation (a $0.5 \mathrm{~cm}$ length of the forearm is irradiated). Bone mineral content results are expressed as ash weight/ unit length of the bones $(\mathrm{mg} / \mathrm{cm})$ and include the mineral content of both the ulna and radius. The scans were performed within two weeks of birth in the liveborn infants and measurements of weight and crown-heel length were taken on the day of the scan. The forearm bones of the stillborn infants were scanned under water after excision and removal of surplus soft tissue. Results of absorptiometry and weight and crown-heel length (CHL) measurements are summarised in tables 2-5.

Most of the statistical analysis is based on linear regression with gestational age at birth as the independent variable. The dependent variable was always subjected to logarithmic transformation before regression analysis. Whenever any regression equation was used to estimate the value of the dependent variable, the value of the independent variable was always within the range of the data on which the regression equation was based.

Table 2 Observations on liveborn Asian singletons. Weight was measured at birth and, when absorptiometry was performed, within two weeks of birth. Where the data are incomplete, the number of infants for whom that mean was computed is given in parentheses

\begin{tabular}{|c|c|c|c|c|c|c|c|}
\hline \multirow{2}{*}{$\begin{array}{l}\text { Gestational } \\
\text { age (weeks) }\end{array}$} & \multirow[t]{2}{*}{ Sex } & \multirow{2}{*}{$\begin{array}{l}\text { No } \\
\text { of } \\
\text { infants }\end{array}$} & \multirow{2}{*}{$\begin{array}{l}\text { At birth } \\
\text { Weight } \\
(\mathrm{g})\end{array}$} & \multicolumn{4}{|c|}{ At absorptiometry } \\
\hline & & & & $\begin{array}{l}\text { Mean time } \\
\text { after birth } \\
\text { (weeks)* }\end{array}$ & $\begin{array}{l}\text { Bone mineral } \\
\text { content } \\
(\mathrm{mg} / \mathrm{cm})\end{array}$ & $\begin{array}{l}\text { Weight } \\
(g)\end{array}$ & $\begin{array}{l}\text { Crown-heel } \\
\text { length } \\
(\mathrm{cm})\end{array}$ \\
\hline 28 & $\mathbf{M}$ & 2 & 975 & 1.5 & $81 \cdot 7$ & 910 & $34 \cdot 9$ \\
\hline 29 & $\mathbf{F}$ & 1 & 750 & 0.7 & $86 \cdot 2$ & 660 & $34 \cdot 3$ \\
\hline 33 & $\mathbf{F}$ & 1 & 750 & $0 \cdot 3$ & $49 \cdot 8$ & 790 & $33 \cdot 0$ \\
\hline 36 & $\mathbf{M}$ & 1 & 1970 & $0 \cdot 6$ & $135 \cdot 1$ & 1920 & $45 \cdot 6$ \\
\hline 37 & $\mathbf{M}$ & 1 & 3040 & $0 \cdot 1$ & $168 \cdot 9$ & 3015 & $48 \cdot 9$ \\
\hline 37 & $\mathbf{F}$ & 1 & 3000 & $0 \cdot 6$ & $132 \cdot 0$ & 3010 & $57 \cdot 0$ \\
\hline 38 & $\mathbf{M}$ & 2 & 3345 & 0.5 & $200 \cdot 5$ & 3185 & $49 \cdot 8$ \\
\hline 39 & $\mathbf{M}$ & 2 & $3000(1)$ & 0.4 & $197 \cdot 2$ & 3245 & $51 \cdot 2$ \\
\hline
\end{tabular}

${ }^{*}$ Time after birth at which measurements were performed. 
Table 3 Observations on white twins. For each pair individual data are given for twins I (firstborn) and II. Weight was measured at birth and in the liveborn infants again when absorptiometry was performed, within two weeks of birth

\begin{tabular}{|c|c|c|c|c|c|c|c|}
\hline \multirow{2}{*}{$\begin{array}{l}\text { Gestational } \\
\text { age (weeks) }\end{array}$} & \multirow[t]{2}{*}{ Twin } & \multirow[t]{2}{*}{ Sex } & \multirow{2}{*}{$\begin{array}{l}\text { At birth } \\
\text { Weight } \\
(\mathrm{g})\end{array}$} & \multicolumn{4}{|c|}{ At absorptiometry } \\
\hline & & & & $\begin{array}{l}\text { Mean time } \\
\text { after birth } \\
\text { (weeks)* }\end{array}$ & $\begin{array}{l}\text { Bone mineral } \\
\text { content } \\
(\mathrm{mg} / \mathrm{cm})\end{array}$ & $\begin{array}{l}\text { Weight } \\
(g)\end{array}$ & $\begin{array}{l}\text { Crown-heel } \\
\text { length } \\
(\mathrm{cm})\end{array}$ \\
\hline & & & & tillbirths & & & \\
\hline \multirow[t]{2}{*}{22} & I & $\mathbf{M}$ & 369 & - & $29 \cdot 1$ & - & $29 \cdot 0$ \\
\hline & II & $\mathbf{M}$ & 355 & - & $27 \cdot 8$ & - & $26 \cdot 0$ \\
\hline \multirow[t]{2}{*}{30} & I & $F$ & 1700 & - & $89 \cdot 1$ & - & $43 \cdot 0$ \\
\hline & II & $\mathrm{F}$ & 985 & - & $68 \cdot 4$ & - & $37 \cdot 5$ \\
\hline \multicolumn{8}{|c|}{ Live births } \\
\hline \multirow[t]{2}{*}{29} & I & $\mathbf{M}$ & 1175 & $0 \cdot 1$ & $73 \cdot 1$ & 1170 & $37 \cdot 5$ \\
\hline & II & $\mathbf{M}$ & 1100 & $2 \cdot 0$ & $77 \cdot 9$ & 1100 & $38 \cdot 6$ \\
\hline \multirow[t]{2}{*}{30} & I & $\mathrm{F}$ & 1400 & $1 \cdot 0$ & $72 \cdot 6$ & 1220 & $39 \cdot 2$ \\
\hline & II & $\mathrm{F}$ & 650 & $1 \cdot 0$ & $61 \cdot 1$ & 730 & $33 \cdot 3$ \\
\hline \multirow[t]{2}{*}{31} & I & $\mathbf{M}$ & 1540 & $1 \cdot 3$ & $96 \cdot 8$ & 1431 & $40 \cdot 0$ \\
\hline & II & $\mathrm{F}$ & 1800 & $1 \cdot 3$ & $115 \cdot 5$ & 1725 & $43 \cdot 1$ \\
\hline \multirow[t]{2}{*}{31} & I & $\mathrm{F}$ & 1350 & $1 \cdot 7$ & $84 \cdot 1$ & 1350 & $40 \cdot 0$ \\
\hline & II & $\mathbf{M}$ & 1400 & $1 \cdot 7$ & $108 \cdot 9$ & 1400 & $38 \cdot 2$ \\
\hline \multirow[t]{2}{*}{32} & I & $\mathbf{M}$ & 1400 & $1 \cdot 4$ & $115 \cdot 6$ & 1360 & $40 \cdot 0$ \\
\hline & II & $\mathbf{M}$ & 2000 & 1.4 & $111 \cdot 1$ & 1710 & $42 \cdot 5$ \\
\hline \multirow[t]{2}{*}{32} & I & $\mathbf{M}$ & 1850 & $1 \cdot 1$ & $153 \cdot 1$ & 1820 & $42 \cdot 8$ \\
\hline & II & $\mathbf{M}$ & 1550 & $1 \cdot 1$ & $131 \cdot 9$ & 1550 & $40 \cdot 4$ \\
\hline \multirow[t]{2}{*}{32} & I & $\mathbf{M}$ & 2000 & $0 \cdot 1$ & $127 \cdot 6$ & 2000 & $42 \cdot 6$ \\
\hline & II & $\mathbf{M}$ & 1800 & $0 \cdot 1$ & $119 \cdot 8$ & 1850 & $43 \cdot 2$ \\
\hline
\end{tabular}

*Time after birth at which measurements were performed.

Table 4 Mean bone mineral white content and crown-heel length in stillborn singletons

\begin{tabular}{|c|c|c|c|c|c|c|}
\hline \multirow{2}{*}{$\begin{array}{l}\text { Gestational } \\
\text { age (weeks) }\end{array}$} & \multicolumn{3}{|c|}{ Boys } & \multicolumn{3}{|c|}{ Girls } \\
\hline & No & $\begin{array}{l}\text { Bone } \\
\text { mineral } \\
\text { content } \\
(\mathrm{mg} / \mathrm{cm})\end{array}$ & $\begin{array}{l}\text { Crown-heel } \\
\text { length } \\
(\mathrm{cm})\end{array}$ & No & $\begin{array}{l}\text { Bone } \\
\text { mineral } \\
\text { content } \\
(\mathrm{mg} / \mathrm{cm})\end{array}$ & $\begin{array}{l}\text { Crown-heel } \\
\text { length } \\
(\mathrm{cm})\end{array}$ \\
\hline 18 & 1 & $19 \cdot 1$ & $22 \cdot 8$ & - & - & - \\
\hline 19 & 1 & 14.4 & $20 \cdot 0$ & - & - & - \\
\hline 22 & 2 & $34 \cdot 2$ & $28 \cdot 5$ & - & - & - \\
\hline 23 & 2 & $32 \cdot 3$ & $28 \cdot 0$ & 1 & $41 \cdot 5$ & - \\
\hline 25 & - & - & - & 2 & $43 \cdot 3$ & $31 \cdot 3$ \\
\hline 26 & 1 & $43 \cdot 6$ & - & - & - & - \\
\hline 27 & 1 & 57.9 & $32 \cdot 5$ & - & - & - \\
\hline 28 & - & - & - & 1 & $24 \cdot 6$ & $37 \cdot 5$ \\
\hline 31 & 1 & 99.9 & $42 \cdot 0$ & - & - & - \\
\hline 33 & 1 & $75 \cdot 9$ & $47 \cdot 0$ & - & - & - \\
\hline 35 & 1 & $143 \cdot 5$ & $48 \cdot 0$ & - & - & - \\
\hline 39 & 1 & $169 \cdot 3$ & $51 \cdot 5$ & - & - & - \\
\hline
\end{tabular}

\section{Results}

\section{WHITE SINGLETONS}

\section{(I) Birthweight}

Mean values of weight at birth in relation to gestational age are given in table 1 and individual values are plotted against gestational age in fig 1 .

Although the form of the true relation in utero between weight and gestational age is unknown, a discontinuity between the data on stillborn and liveborn infants with a change in gradient at about 30 weeks' gestational age is shown (fig 1); below 30 weeks most infants were stillborn (12 out of 21 cases) and at and above 30 weeks most were liveborn (48 out of 52 cases).

Because in this set of data there was no detectable systematic difference in birth weight between boys and girls, the data were pooled. Birth weight 
Table 5 Mean bone mineral content, weight, and crown-heel length in liveborn white singletons. The data are complete for all infants. In contrast with table 1, mean weight values given below were obtained from measurements taken on the day of the measurement of bone mineral content

\begin{tabular}{|c|c|c|c|c|c|c|c|c|c|c|}
\hline \multirow{2}{*}{$\begin{array}{l}\text { Gestational } \\
\text { age (weeks) }\end{array}$} & \multicolumn{5}{|c|}{ Boys } & \multicolumn{5}{|c|}{ Girls } \\
\hline & $N o$ & $\begin{array}{l}\text { Mean time } \\
\text { after birth } \\
\text { (weeks)* }\end{array}$ & $\begin{array}{l}\text { Bone } \\
\text { mineral } \\
\text { content } \\
(\mathrm{mg} / \mathrm{cm})\end{array}$ & $\begin{array}{l}\text { Weight } \\
(g)\end{array}$ & $\begin{array}{l}\text { Crown-heel } \\
\text { length } \\
(\mathrm{cm})\end{array}$ & No & $\begin{array}{l}\text { Mean time } \\
\text { after birth } \\
\text { (weeks)* }\end{array}$ & $\begin{array}{l}\text { Bone } \\
\text { mineral } \\
\text { content } \\
(\mathrm{mg} / \mathrm{cm})\end{array}$ & $\begin{array}{l}\text { Weight } \\
\text { (g) }\end{array}$ & $\begin{array}{l}\text { Crown-heel } \\
\text { length } \\
(\mathrm{cm})\end{array}$ \\
\hline 26 & - & - & - & - & - & 1 & 1.7 & $93 \cdot 0$ & 700 & $32 \cdot 3$ \\
\hline 27 & - & - & - & - & - & 3 & $1 \cdot 1$ & $78 \cdot 7$ & 1008 & $37 \cdot 8$ \\
\hline 28 & 2 & $1 \cdot 8$ & $107 \cdot 0$ & 1250 & $38 \cdot 3$ & - & - & - & - & - \\
\hline 29 & 1 & 1.4 & $104 \cdot 4$ & 1400 & 39.7 & 2 & $1 \cdot 2$ & $116 \cdot 0$ & 1475 & $39 \cdot 3$ \\
\hline 30 & 2 & 0.4 & $122 \cdot 6$ & 1605 & $41 \cdot 8$ & 2 & $1 \cdot 6$ & $111 \cdot 1$ & 1305 & 40.9 \\
\hline 31 & 3 & 0.7 & $92 \cdot 5$ & 1570 & 40.9 & 6 & $1 \cdot 5$ & $96 \cdot 6$ & 1362 & $40 \cdot 8$ \\
\hline 32 & 2 & $1 \cdot 5$ & $154 \cdot 5$ & 1953 & $43 \cdot 6$ & 5 & 0.7 & $130 \cdot 5$ & 1786 & $43 \cdot 4$ \\
\hline 33 & - & - & - & - & - & 2 & 0.5 & $167 \cdot 0$ & 2200 & $42 \cdot 8$ \\
\hline 34 & 1 & 0.7 & $173 \cdot 3$ & 2600 & $45 \cdot 8$ & - & - & - & - & - \\
\hline 35 & - & - & - & - & - & 1 & 0.6 & $198 \cdot 3$ & 2570 & $47 \cdot 5$ \\
\hline 36 & - & - & - & - & - & 1 & 0.9 & 161.9 & 2580 & $46 \cdot 6$ \\
\hline 38 & 1 & 0.6 & $217 \cdot 5$ & 3030 & $49 \cdot 0$ & 1 & $0 \cdot 1$ & $191 \cdot 8$ & 2980 & $51 \cdot 0$ \\
\hline 39 & 4 & 0.5 & $203 \cdot 1$ & 3580 & $50 \cdot 8$ & - & - & - & - & - \\
\hline 40 & 5 & 0.6 & $218 \cdot 7$ & 3754 & 53.5 & 6 & $0 \cdot 3$ & $198 \cdot 0$ & 3503 & $54 \cdot 2$ \\
\hline 41 & - & - & - & - & - & 2 & $0 \cdot 2$ & 194.9 & 3945 & $57 \cdot 5$ \\
\hline 42 & 1 & $0 \cdot 1$ & $205 \cdot 8$ & 3700 & $51 \cdot 0$ & 1 & 0.7 & $261 \cdot 1$ & 3510 & $51 \cdot 3$ \\
\hline 43 & 2 & 0.5 & 229.0 & 4185 & $56 \cdot 5$ & - & - & - & - & - \\
\hline
\end{tabular}

*Time after birth at which measurements were performed.

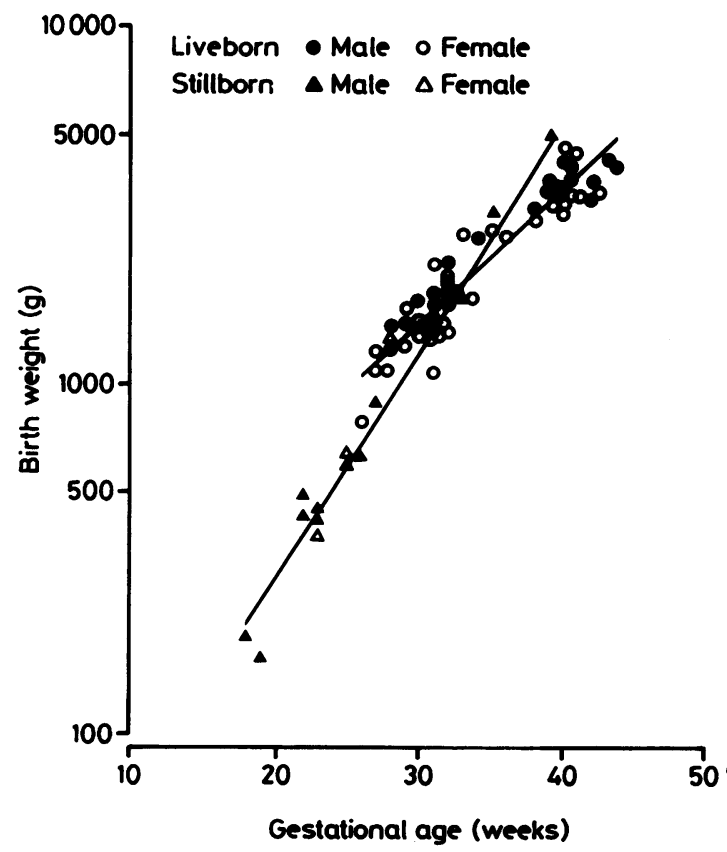

Fig 1 Weight at birth in relation to gestational age in white singleton stillborn and liveborn infants. A log scale has been used on the $y$ axis.
(BWt g) can be estimated from gestational age (GA weeks) using the equations:

Stillborn infants: $\log (\mathrm{BWt})=1 \cdot 168+0 \cdot 0644$.GA $(\mathrm{r}=0.98, \mathrm{p}<0.001)$

Liveborn infants: $\log (\mathrm{BWt})=2 \cdot 040+0 \cdot 0379 . \mathrm{GA}$ $(\mathrm{r}=0.95, \mathrm{p}<0.001)$

Logs are to the base 10 . The regression lines are shown in fig 1 . The standard errors of estimate for $\log (\mathrm{BWt})$ are 0.0858 and 0.0652 for the stillborn and liveborn infants respectively.

(2) Anthropometric data at time of absorptiometry Absorptiometry was performed within two weeks of birth, and crown-heel length was measured on the same day. The mean time since birth of the crownheel length measurements was 0.8 weeks in the liveborn white boy singletons and 0.9 weeks in the liveborn girls. A plot of the crown-heel length measurements against gestational age is shown (fig 2). Like fig 1 , it shows a change in gradient between the data on stillborn and liveborn infants.

Crown-heel length can be estimated from gestational age at birth using the equations:

Stillborn infants: $\log (\mathrm{CHL})=1 \cdot 006+0 \cdot 0193$.GA $(\mathrm{r}=0.97, \mathrm{p}<0.001)$

Liveborn infants: $\log (\mathrm{CHL})=1 \cdot 251+0 \cdot 0118$.GA $(r=0.95, p<0.001)$ 


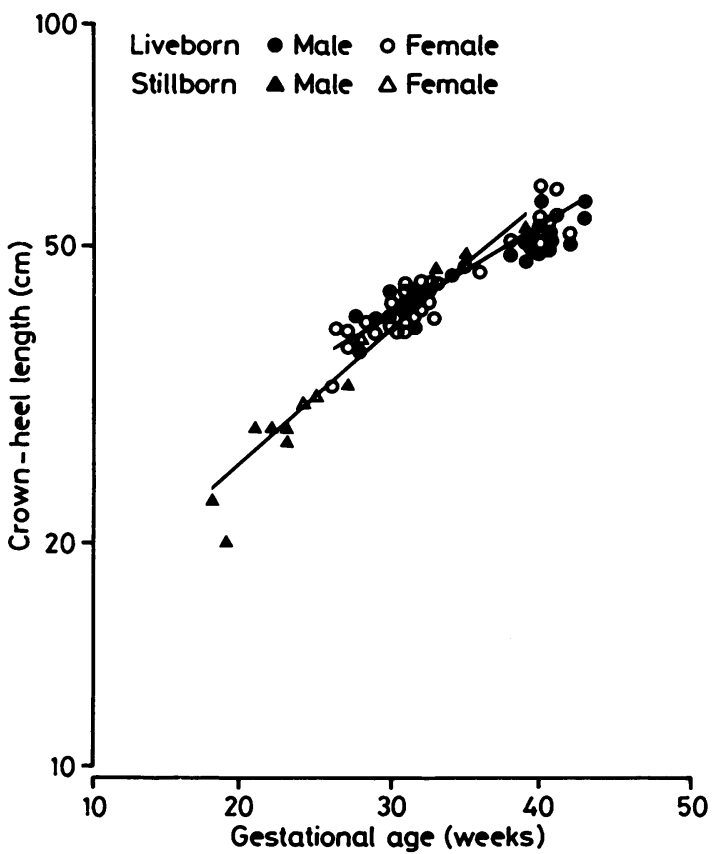

Fig 2 Crown-heel length, measured when absorptiometry was performed, in relation to gestational age in white singleton stillborn and liveborn infants. A log scale has been used on the $y$ axis.

The standard errors of estimate are 0.030 and 0.021 respectively. The regression lines are shown in fig 2 .

In the interval between birth and absorptiometry the weight in the boys decreased on average by a mean (SE) $31.2(13.2) \mathrm{g}(\mathrm{p}<0.05)$ and in girls it decreased by $51.3(20.9) \mathrm{g}(\mathrm{p}<0.02)$. For the two sexes pooled the mean decrease in weight was $43 \cdot 3$ $(13 \cdot 6) \mathrm{g}(\mathrm{p}<0 \cdot 01)$.

\section{(3) Absorptiometric data}

Individual data of bone mineral content obtained within two weeks of birth are plotted against gestational age (fig 3), and separate regression lines are shown for data on stillborn and liveborn infants. Estimates of bone mineral content (BMC) $(\mathrm{mg} / \mathrm{cm})$ from gestational age (GA weeks) can be obtained using the equations:

Stillborn infants: $\log (\mathrm{BMC})=0 \cdot 437+0 \cdot 0465$.GA $(r=0.91, p<0.001)$

Liveborn infants: $\log (\mathrm{BMC})=1 \cdot 179+0 \cdot 0285$.GA $(\mathrm{r}=0.85, \mathrm{p}<0.001)$

The standard errors of estimate are respectively $0 \cdot 126$ and $0 \cdot 090$. The regression lines are shown in fig 3 ; the discontinuity between the data on stillborn

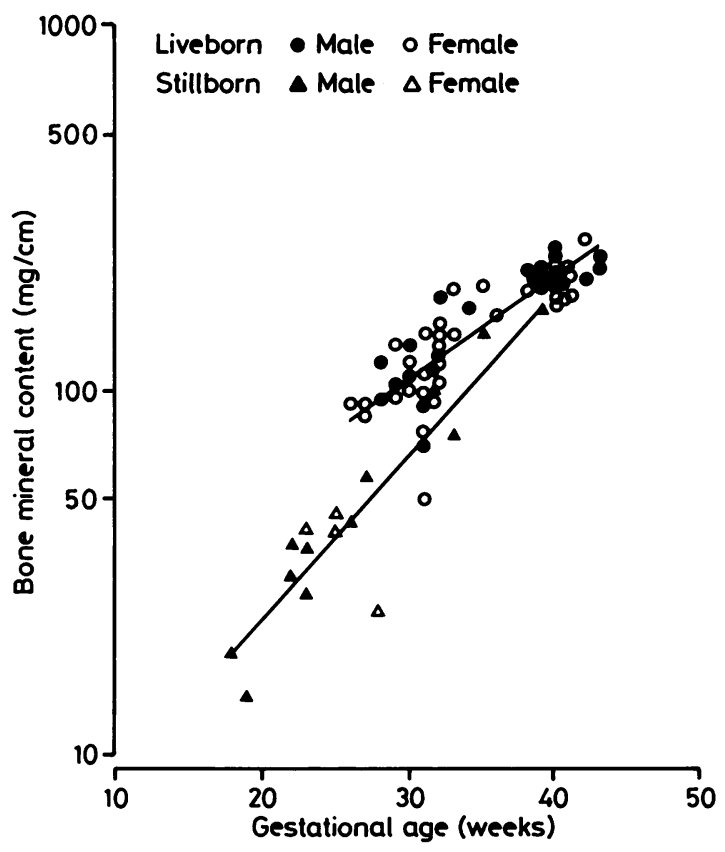

Fig 3 Bone mineral content of the mid forearm, measured within two weeks of birth, in relation to gestational age in white singleton stillborn and liveborn infants. A log scale has been used on the $y$ axis.

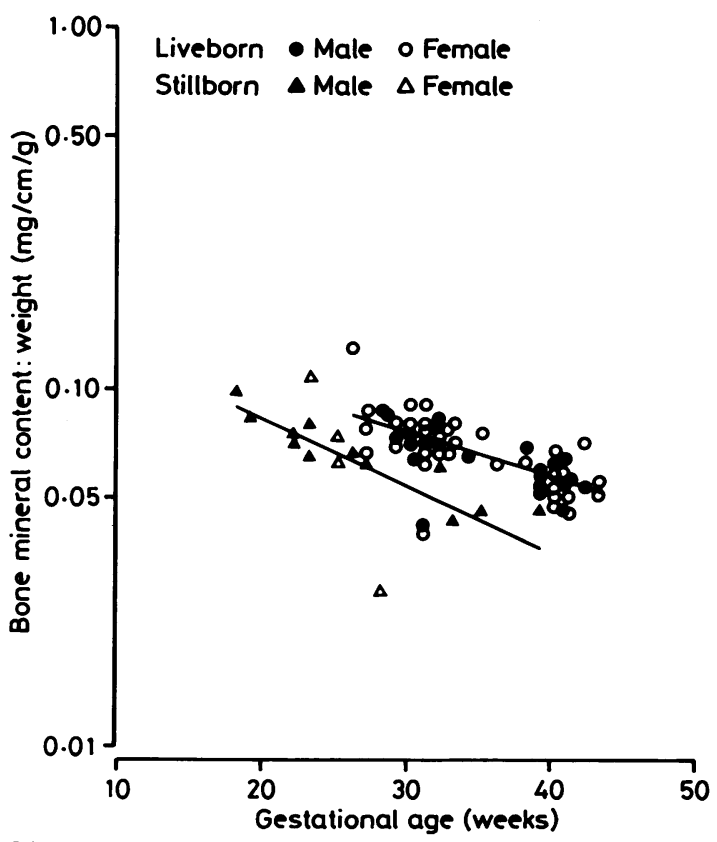

Fig 4 Bone mineral content:weight ratio in relation to gestational age in white singleton stillborn and liveborn infants. A log scale has been used on the y axis. 
and liveborn infants is clear. In contrast with the relation between weight at birth and crown-heel length with gestational age (figs 2 and 3), the discontinuity is shown as a displacement rather than a change in gradient. In the region where the stillborn and liveborn groups overlapped (around 30 weeks' gestational age), bone mineral content was substantially lower in the stillborn infants than in the liveborn infants. Using the equations of the regression lines given above to estimate bone mineral content at a gestational age of 30 weeks, the estimate for stillborn infants was $67.9 \mathrm{mg} / \mathrm{cm}$ and for liveborn infants was $108.1 \mathrm{mg} / \mathrm{cm}$; values for bone mineral content in stillborn infants were on average $37 \%$ lower than in liveborn infants at 30 weeks' gestation.

The regression equation for liveborn infants indicated that a bone mineral content value of 88 $\mathrm{mg} / \mathrm{cm}$ (midway between the two estimates quoted above) would be reached at about 27 weeks' gestation by a fetus that is subsequently prematurely liveborn. The regression line for stillborn infants indicated that this bone mineral content value would be reached at about 33 weeks' gestation (if the fetus had not already died), that is, about six weeks later than in the viable fetus.

The difference between stillborn and liveborn infants is further emphasised when individual data for the ratio bone mineral content (BMC):weight (at time of absorptiometry) are plotted against gestational age (fig 4). The data on liveborn infants indicated that bone mineral content does not increase in proportion to weight during 'normal' development in utero; there was a significant inverse correlation between log (BMC:weight) and gestational age. The data on stillborn infants were, with few exceptions, at all gestational ages lower than the data on liveborn infants; again, an inverse correlation was observed. The equations of the regression lines shown in fig 4 are:
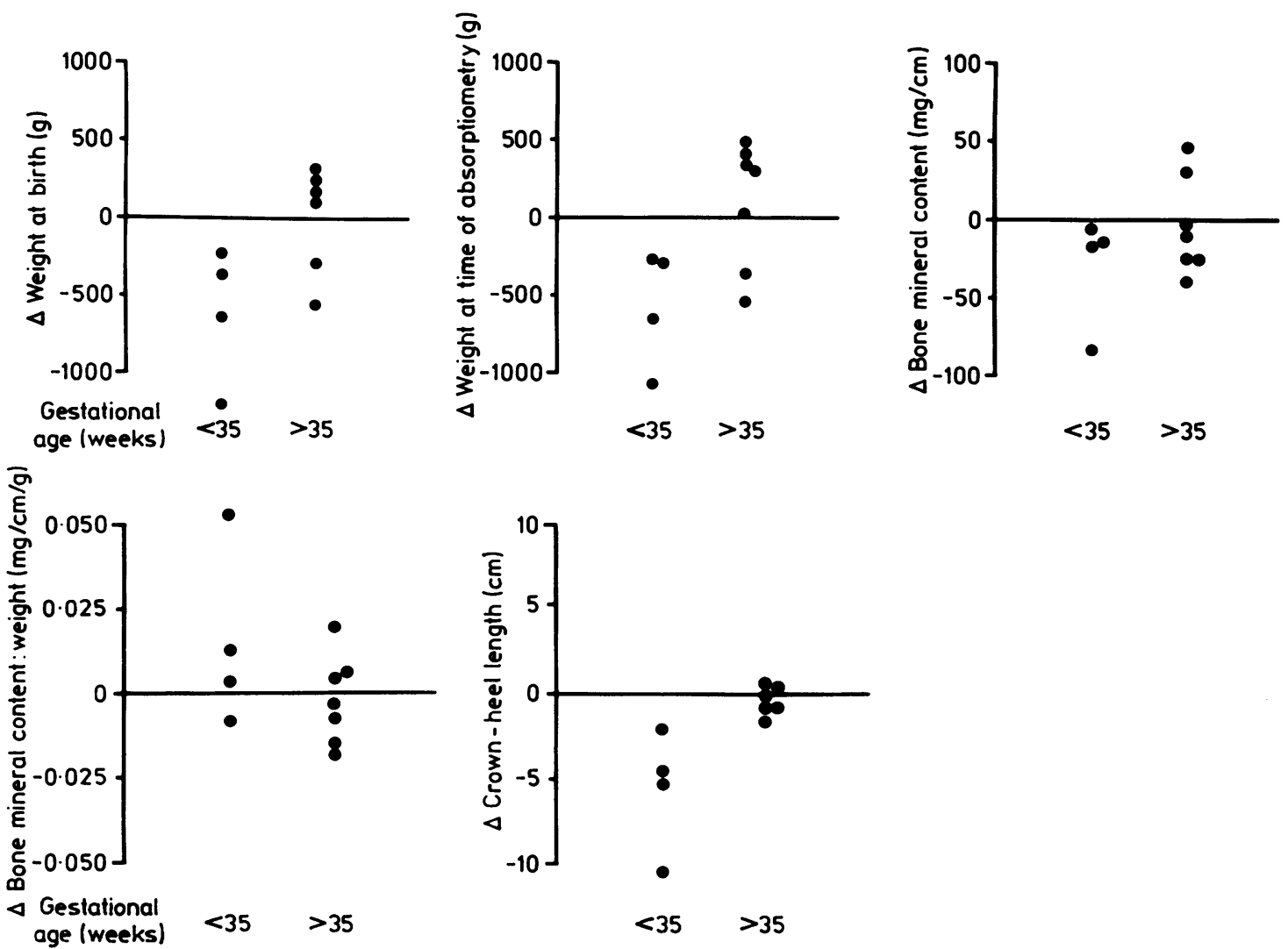

Fig 5 Deviations $(\triangle)$ of measured values in liveborn Asian singletons from expected values in liveborn white singletons. 
Stillborn infants:

$\log (\mathrm{BMC}:$ weight $)=-0 \cdot 735-0 \cdot 0178 . \mathrm{GA}$

$$
\mathrm{r}=0.57, \mathrm{p}<0.02 \text { ) }
$$

Liveborn infants:

$$
\begin{gathered}
\log (\mathrm{BMC}: \text { weight })=-0 \cdot 775-0.0121 . \mathrm{GA} \\
(\mathrm{r}=0.65, \mathrm{p}<0 \cdot 001)
\end{gathered}
$$

The standards errors of estimate are $0 \cdot 154$ and $0 \cdot 071$ respectively.

\section{ASIAN SINGLETONS}

Individual data on Asian singletons, split into groups below and above 35 weeks' gestational age, are shown in fig 5. The results are expressed as deviations from the appropriate regression line; a positive deviation is such that the measured value exceeds the expected value predicted by the regression equation.

Most of the infants in the group over 35 weeks' gestational age compared closely with liveborn white infants with respect to weight at birth, weight at the time of absorptiometry, bone mineral content, bone mineral content:weight, and crown-heel length. Accepting the possibility that the gestational ages might be inaccurate, liveborn Asian infants under 35 weeks' gestational age were in the main smaller in every respect than their white counterparts, although the number of cases examined was too small for statistical analysis; in all cases, body weight and bone mineral content were below the expected values for liveborn white infants. The ratio of bone mineral content:weight was close to the expected value in three out of the four cases with both measurements.

WHITE TWINS

Individual data expressed as deviations from the appropriate regression line are plotted in fig 6 .

\section{(1) Stillbirths}

Results on the two pairs of stillborn white twins expressed as deviations from the regression lines for
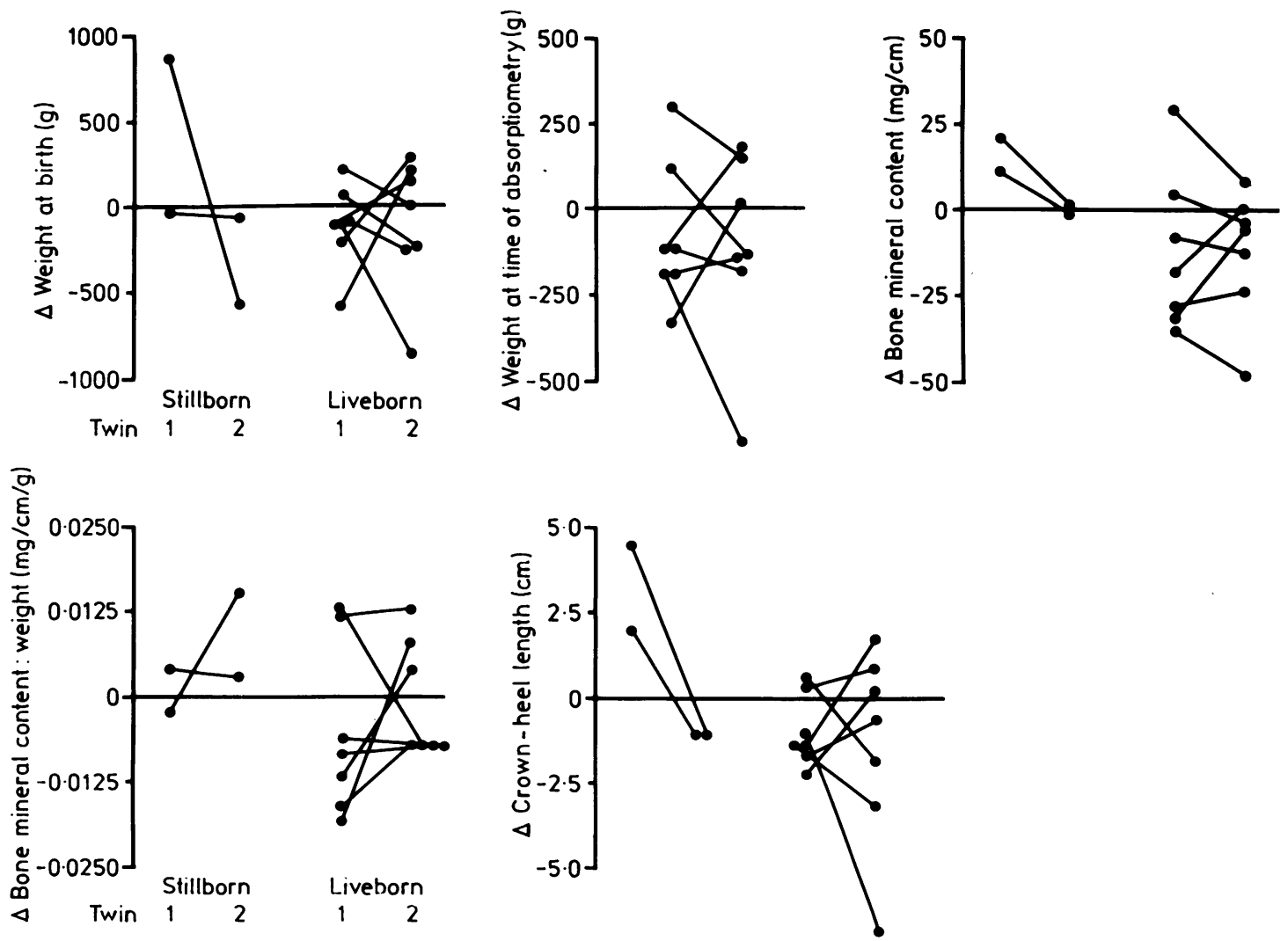

Fig 6 Deviations $(\triangle)$ of measured values in stillborn and liveborn white twins from expected values in white singletons of similar type. Values for the first born twin are on the left for each pair. 
stillborn white singletons showed no evidence of systematic bias, either positive or negative.

\section{(2) Live births}

With the exception of one second born girl twin, the measurements on liveborn white twins compared closely with expected values in liveborn white singletons with respect to body weight at birth, crown-heel length, weight at the time of absorptiometry, bone mineral content, and bone mineral content:weight. The exceptional twin (gestational age 30 weeks) had reduced body weight, crown-heel length, and bone mineral content.

\section{Discussion}

Because photon absorptiometry has been shown to be superior to radiological and biochemical methods in the diagnosis of osteopenia of prematurity ${ }^{3}$ it is important to establish a 'normal' intrauterine mineral accretion curve as an adjunct to the investigation and treatment of infants at risk of developing postnatal osteopenia. The above results, obtained as part of a larger series of investigations of bone mineralisation in the neonate, provide the required reference values together with standard anthropometric data in the same individuals.

In this study the relation between birth weight and gestational age for liveborn white infants was found to be exponential (fig 1). A similar relation in a larger series has previously been reported by Shaw. ${ }^{7}$ Comparison of the relations between birth weight and gestational age for stillborn and liveborn white infants, however, showed a disparity in our data. At comparable gestational ages, stillborn infants tended to have lower birth weights than liveborn infants. Observations of crown-heel length, reduced in stillborn compared with liveborn infants, provided corroborative evidence of intrauterine growth retardation (fig 2).

Also with respect to body weight, our data indicated as expected a loss between birth and the time at which absorptiometry was performed (less than two weeks after birth). Weight loss in the first week of life is usual.

In liveborn white infants born between 26 and 43 weeks' gestation the relation between bone mineral content in the forearm and gestational age was found to be curvilinear and was fitted to an exponential function (fig 3). Greer $\mathrm{et} \mathrm{al} \mathrm{also} \mathrm{found} \mathrm{a}$ curvilinear function to provide a better fit to similar data than a linear function. ${ }^{8}$ Over smaller gestational age ranges, however, the relation can appear to be linear. ${ }^{2}$ It is possible that bone mineralisation in reality follows different types of growth curve at different sites in the skeleton. For example, Vyhmeister et al measured bone mineral content at the midshaft of the humerus in 148 infants between 26 and 42 weeks' gestation, and concluded that their data could be described equally well by linear or curvilinear functions. ${ }^{9}$ Although the shapes of growth curves obtained from different sources might differ in detail, the point is illustrated (fig 7) that the relative magnitudes of the changes in mineralisation observed between gestational ages of 24 and 40 weeks are comparable, particularly over 28 weeks' gestation. Like our data for bone mineral content, anthropometric measurements increased exponentially with gestational age as did those reviewed by Shaw. ${ }^{7}$

Because almost all the body's calcium is found in the skeleton, total body calcium content provides an alternative to local bone mineral content as a measure of general skeletal mineralisation. In his analysis of selected data from the literature, Shaw found an exponential relation between fetal total body calcium content and gestational age. ${ }^{10} \mathrm{Simi}-$ larly, Forbes examined data for total body calcium content from five other sources and came to the same conclusion. ${ }^{11}$ Ziegler $e t$ al analysed a further set of data, fitted modified exponential functions to several growth related variables, and presented

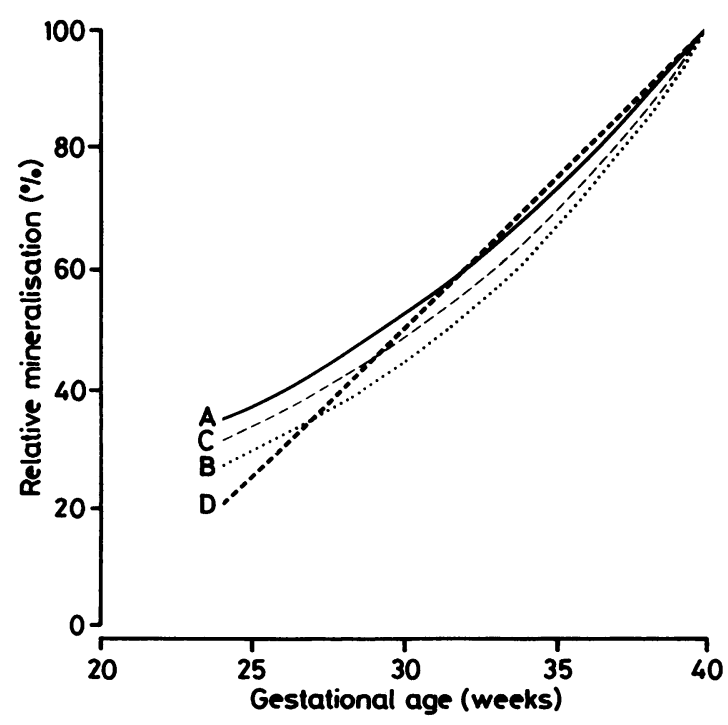

Fig 7 Comparison of bone mineralisation growth curves from three sources, all normalised to $100 \%$ at the gestational age of 40 weeks. (A) Curve for the mid-forearm presented in this paper; $(B)$ curve for the forearm (distal one third) published by Minton et al ${ }^{2}$; $(C)$ curve for the humerus published by Vyhmeister et al ${ }^{9}$; (D) straight line fitted by Vyhmeister et al to the same data as curve $(C) .^{9}$ 
tables of values of the variables in relation to gestational age. ${ }^{12}$ The results of the above mentioned studies were reasonably consistent, with the total body calcium content in a full term infant being about $30 \mathrm{~g}$. At 24 weeks' gestation total body calcium content was found to be only $10-15 \%$ of its value at full term.

In contrast, bone mineral content (in the forearm) has by that stage reached about $35 \%$ of its full term value. Thus although at any particular value of gestational age it is still possible that in a group of infants bone mineral content is linearly related to total body calcium content, it seems unlikely that the equation of such a line is independent of gestational age. It might therefore be dangerous to regard a change in bone mineral content (observed over a span of gestational ages) as an estimator of change in total body calcium content. This reservation is, however, based on measurements of total body calcium content in groups including stillborn infants which, as we have shown, are likely to have undermineralised bones.

Our measurements of bone mineral content in stillborn infants were consistently lower than the values predicted from the relation between bone mineral content and gestational age observed in liveborn infants (figs 3 and 4). A regression equation was evaluated for the stillborn group, but it should not be taken to describe the way bone mineral content changed with gestational age in the individual infants before being stillborn. Although the possibility of demineralisation after death cannot be excluded, this line is more likely to be the result of observing a heterogeneous group of infants in which individuals fell progressively further below the 'normal' curve as they grew. If that interpretation is correct, each individual result might be a direct manifestation of a general disorder of calcium metabolism in utero and it is possible that such a condition might be a factor contributing to the risk of stillbirth.

It has already been noted above that stillborn infants are relatively short in stature, and on that basis it might seem reasonable to have taken crownheel length into account when comparing stillborn with liveborn infants. Crown-heel length, however, is dependent on the size of the skeleton, as is bone mineral content, and there is a continuous relation in utero between the two variables in infants subsequently liveborn. We think it is likely that in infants subsequently stillborn the relation might be the same-that is, that the skeletal mineralisation defect associated with stillbirth affects both crownheel length and bone mineral content. In that situation, the only way the defect can be detected is by examining the measurements of bone mineral content in relation to gestational age alone, and we therefore chose not to take crown-heel length into account when comparing the stillborn and liveborn groups.

The observation of retarded mineralisation in stillborn infants has important implications regarding daily calcium requirement in premature infants. Some authors have based their estimates of requirement on the change in total body calcium content between a given gestational age and full term, ${ }^{\circ}$ but the change is calculated from measurements on infants including stillborn cases. ${ }^{13}{ }^{14}$ Consequently the daily calcium requirement of $120-130 \mathrm{mg} / \mathrm{kg} /$ day is likely to be an overestimate because data from stillborn infants in the earlier gestational age groups will bias the mean total body calcium content downwards and as a result the calculated increment in total body calcium content between birth and full term will be too large. Given the patient management problems created by dietary calcium supplementation, which might include acidosis and hypercalcaemia, any reduction in calcium intake that remains consistent with the infant's true requirement is advantageous.

In an early study using the same technique we showed bone mineral content to be closely similar in full term Asian and white infants. ${ }^{15}$ The data in this study for Asian infants born after 35 or more weeks' gestation were consistent with the previous conclusion. Below the gestational age the Asian infants tended to have lower values for bone mineral content and weigh less than their white counterparts; the few data available suggested that the values for bone mineral content were more appropriate to body weight than recorded gestational age.

Measurements on twins showed no mineralisation deficit relative to their singleton peers. One twin showed signs of nutritional compromise in utero, mimicking the findings in stillborn white singletons.

The authors are indebted to Margaret Simpson (University Department of Medical Physics, Leeds) who collated and carried out the statistical analysis of the data.

A Horsman, $\mathbf{J}$ Truscott, and $\mathbf{M}$ Simpson are employed by the Medical Research Council and supported under an External Scientific Staff grant. S Ryan is supported by an award from the Local Trustees in The General Infirmary at Leeds.

\footnotetext{
References

' Steichen JJ, Gratton T, Tsang RC. Osteopenia of prematurity: the cause and possible treatment. J Pediatr 1980;96:528-34.

2 Minton SD, Steichen JJ, Tsang RC. Bone mineral content in term and preterm appropriate-for-gestational-age infants. $J$ Pediatr 1979;95:1037-42.

3 James JR, Congdon PJ, Truscott J, Horsman A, Arthur R. Osteopenia of prematurity. Arch Dis Child 1986;61:871-6.
} 
4 James JR, Truscott J, Congdon PJ, Horsman A. Measurement of bone mineral content in the human fetus by photon absorptiometry. Early Hum Dev 1986;13:169-81.

5 Greer FR, Tsang RC. Calcium, phosphorus, magnesium and vitamin D requirements for the preterm infant. In: Tsang RC, ed. Vitamin and mineral requirements in preterm infants. New York: Marcel Dekker Inc, 1985:99-136.

6 Gairdner D, Pearson J. A growth chart for premature and other infants. Arch Dis Child 1971;46:783-7. (Revised, Ware: Castlemead Publications, 1985.)

7 Shaw JCL. Parenteral nutrition in the management of sick low birthweight infants. Pediatr Clin North Am 1973;20:333-58.

${ }^{8}$ Greer FR, Lane J, Weiner S, Mazess RB. An accurate and reproducible absorptiometric technique for determining bone mineral content in newborn infants. Pediatr Res 1983;17:259-62.

9 Vyhmeister NR, Linkhart TA, Hay S, Baylink DJ, Ghosh B. Measurement of bone mineral content in the term and preterm infant. Am J Dis Child 1987;141:506-10.

${ }^{10}$ Shaw JCL. Evidence for defective skeletal mineralisation in low birth weight infants: the absorption of calcium and fat. Pediatrics 1976;57:16-25.

1 Forbes GB. Calcium accumulated by the human fetus. Pediatrics 1976;57:976-7.

12 Ziegler EE, O'Donnel AM, Nelson SE, Fomon SJ. Body composition of the reference fetus. Growth 1976;40:329-41.

13 Widdowson EM, Spray CM. Chemical development in utero. Arch Dis Child 1951;26:205-14.

14 Givens MH, Macy IG. The chemical composition of the human fetus. J Biol Chem 1933:102:7-17.

15 Congdon PJ, Horsman A, Kirby P, Dibble J, Bashir T. Mineral content of the forearms of babies born to Asian and Caucasian mothers. $\mathrm{Br}$ Med J 1983;286:1233-5.

Correspondence to Dr S Ryan, Regional Neonatal Surgical and Intensive Care Unit, Clarendon Wing, Leeds General Infirmary, Belmont Grove, Leeds LS2 9NS.

Accepted 2 March 1988 